\title{
REVERSIBLE ECTOPIC SOFT TISSUE OSSIFICATION FOLLOWING MEASLES ENCEPHALOMYELITIS
}

\author{
BY \\ PHILIP JACOBS \\ From the Royal Orthopaedic Hospital, Birmingham
}

(RECEIVED FOR PUBLICATION AUGUST 22, 1961)

For many years it has been recognized that changes may take place in the skeletal bony and soft tissues in paraplegic patients. Madame Déjerine and her co-workers described such changes in 1918 and 1919 (Déjerine and Ceillier, 1918; Déjerine, Ceillier and Déjerine, 1919). War injuries, road and industrial accidents have been responsible for an increased number of paraplegic patients, many of whom are young and otherwise healthy. The increasing use of radiography has also contributed to our assessment of the problem. Lodge (1956) has written a valuable paper on the subject based on his review of $x$-ray findings in 236 paraplegic subjects. The pathogenesis of the condition remains a mystery. Clinically the lesion occurs in patients suffering a spinal cord lesion with paraplegia in flexion leading to muscle spasm. Recumbency, promoting the mobilization of calcium from the bones, is probably a factor.

Paraplegia in childhood is a relatively uncommon condition and there are few instances reported of soft tissue ossification accompanying paraplegia in childhood. No less an authority than Caffey (1961) has stated that he has not seen these soft tissue changes in children suffering from paraplegia. Lorber (1953) has reported the condition as a complication of the paraplegia associated with tuberculous meningitis treated with streptomycin.

It is the purpose of this paper to record the history of a child who developed ectopic ossification round the hips following paraplegia secondary to measles encephalomyelitis, and to report that almost complete recovery from the lesions ensued. This is the first known report of this condition arising as a complication of measles.

\section{Case Report}

A 5-year-old girl was admitted to hospital on March 23, 1955 , in a semicomatose state following an attack of measles some days previously. She gradually became unconscious, her arms were spastic and her legs rigid. The cerebrospinal fluid contained 4 lymphocytes and
$65 \mathrm{mg}$. protein per $100 \mathrm{ml}$. A diagnosis of measles encephalomyelitis was made.

She began to recover consciousness after seven weeks and was very noisy and irritable for the following three weeks. Gradually signs of recovery were seen. Function in the arms recovered first.

Spastic contractures in the legs persisted longer and the child was admitted to an orthopaedic hospital for possible treatment of muscle contractures. At this stage the hips were stiff in $30^{\circ}$ flexion deformity and the knees stiff in $10^{\circ}$ flexion deformity. All movements were limited to a few degrees only and were very painful.

A radiograph on September 21, 1955 (Fig. 1), showed well-established soft tissue ossification round both hips. Bones were also a little osteoporotic.

The child was treated conservatively using appropriate splintage and physiotherapy. Gradual and continued recovery resulted. Movements slowly returned to the hips and knees, and in three years following the illness movements were virtually completely restored.

A radiograph on February 9, 1956 (Fig. 2), showed definite evidence of early resorption of ectopic bone around the right hip.

A further radiograph on April 2, 1957 (Fig. 3), showed very marked resorption of ectopic bone around the right hip and substantial resorption of ectopic bone around the left hip, and a radiograph taken on October 21, 1958 (Fig. 4), shows that the merest trace of ectopic bone remains on the right side, and a small flake of bone only is seen on the left side below the acetabulum.

\section{Discussion}

Lesions in paraplegic patients may be summarized as follows:

(1) Changes in bones: (a) osteoporosis; fractures may occur as an occasional complication; (b) erosions over pressure points, e.g. sacrum, greater trochanter or ischial tuberosity.

(2) Changes in joints: absent or minimal. Neurotrophic changes do not occur since the paraplegic joint is not subjected to weight bearing.

(3) Changes in soft tissues: ossification and calcification around the hips or less commonly around the knees and in the thighs. 


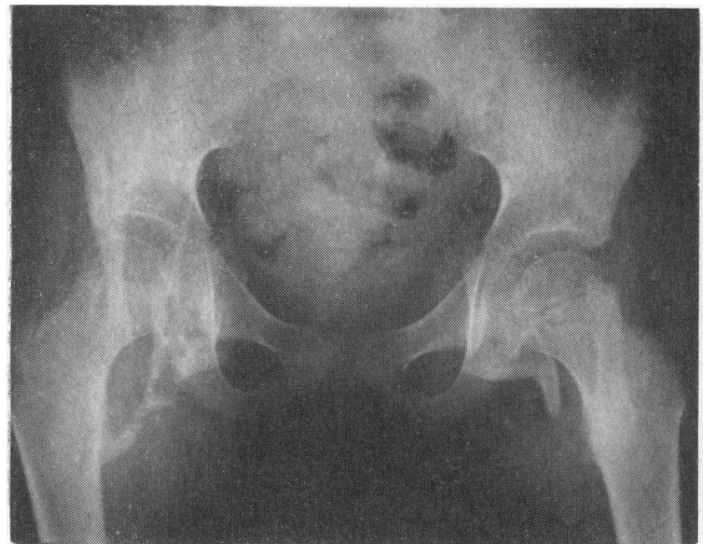

FIG. 1.-Radiograph of pelvis (September 21, 1955). Extensive soft tissue ossification around both hips is shown.

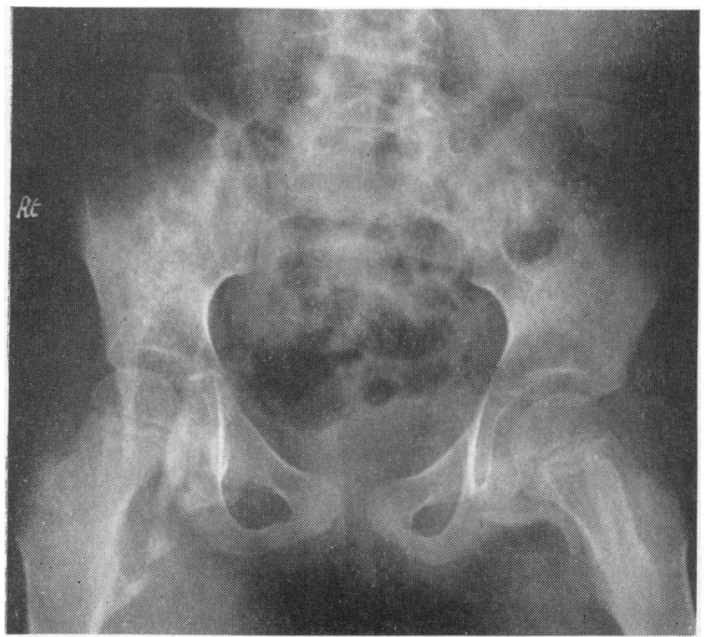

FIG. 2.-Radiograph of pelvis (February 9, 1956), showing early resorption of ectopic bone on the right side both antero-superiorly and inferiorly near the lesser trochanter.

Lodge (1956) has shown that the new bone may appear round the hip in three places: (a) Anteriorly where massive plaques of bone may form from the region of the anterior inferior iliac spine down to the inter-trochanteric line. (b) Posteriorly from the ischium to the posterior part of the greater trochanter. (c) Inferiorly where a more slender bridge of bone passes from the inferior pubic ramus to the lesser trochanter.

Lodge $(1955,1956)$ has stated that the changes in adults are irreversible; masses of ossification form rapidly until they reach a certain size and then

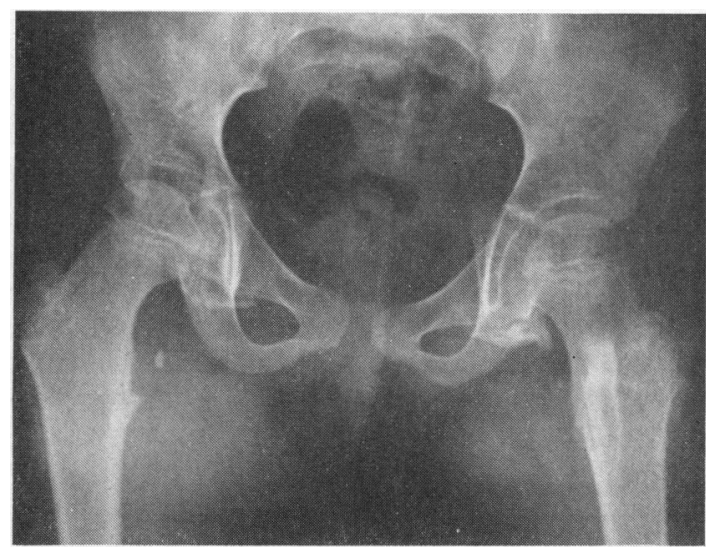

FIG. 3.-Radiograph of pelvis (April 2, 1957). Marked resorption of ectopic bone has occurred on the right side. Considerable resorption of the ectopic bone has also occurred on the left side.

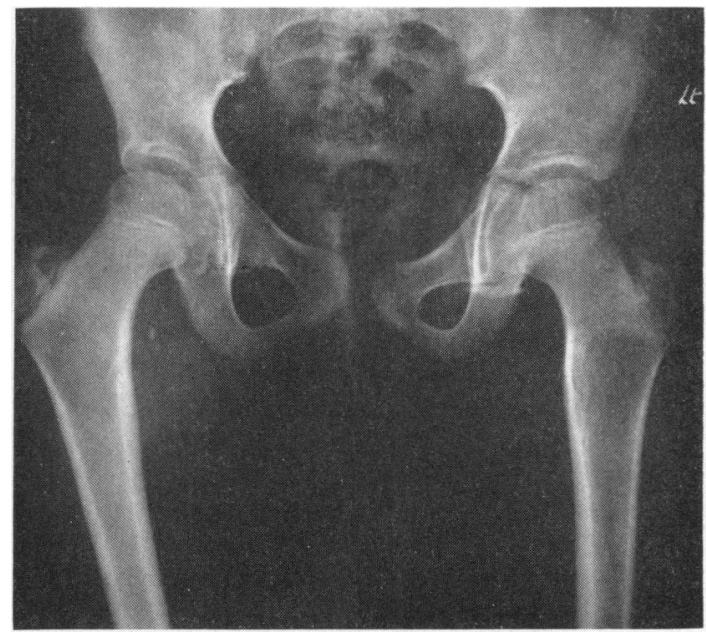

FIG. 4.-Radiograph (October 21, 1958), showing almost complete resorption of ectopic bone. A minute fleck remains on the right side and a small fragment below the left acetabulum persists.

remain static. The patients in Lodge's series were all adults suffering from irreversible paraplegia.

In our patient the ossification was extensive (Fig. 1). Large hood-like plaques of new bone were seen on both sides, on the right side extending from the region of the anterior inferior iliac spine to the femoral neck anteriorly. In addition, more slender bridges of new bone were shown passing from the ischium to the lesser trochanter on either side. This latter type of ossification is well seen in Lorber's patients suffering from tuberculous meningitis.

In two patients described by Lorber some absorp- 
tion of new bone was demonstrated. This resorption was far less complete than in our patient. Our patient made a complete recovery clinically and almost complete resorption of ectopic bone ensued (Fig. 4).

One may therefore expect resorption of ectopic bone in these patients should the neurological lesion be reversible. This finding is important in deciding the correct management of such a patient. Lorber reported one patient in whom operative removal of ectopic bone was undertaken. This led to further deposition of new bone and it was considered that surgical intervention did more harm than good.

\section{Summary}

A case is reported of ectopic soft tissue ossification around the hips in a child who suffered from measles encephalomyelitis. This is the first known report of such a complication of measles.
Almost complete resorption of the ectopic bone occurred following conservative measures. It appears that if recovery from the paraplegia is possible, the laying down of new bone is a reversible process.

Operative removal of ectopic bone is contraindicated.

It is a pleasure to thank Mr. F. G. Allan for permission to publish this report. I am most grateful to Dr. T. Lodge who saw the radiographs and gave me valuable advice.

\section{REFERENCES}

Caffey, J. (1961). Pediatric X-ray Diagnosis, 4th ed., p. 764. Year Book Medical Publishers, Chicago.

Déjerine (Mme) and Ceillier, A. (1918). Para-ostéo-arthropathies des paraplégiques par lésion médullaire (étude clinique et des paraplégiques par lésion médu
radiographique). Ann. méd., 5, 497 .

radiographique). Ann. méd, 5, 497 . paraplégiques par lésion médullaire. Étude anatomique et histologique. Rev. neurol., 35, 399.

Lodge, T. (1955). Recent Advances in Radiology, 3rd ed., p. 75-8. Churchill, London.

(1956). Bone, joint and soft tissue changes following paraplegia. Acta radiol. (Stockh.), 46, 435.

Lorber, J. (1953). Ectopic ossification in tuberculous meningitis. Arch. Dis. Childh., 28, 98. 